\title{
Sepsis is associated with mitochondrial DNA damage and a reduced mitochondrial mass in the kidney of patients with sepsis-AKI
}

Elisabeth C. van der Slikke ${ }^{1} \mathbb{C}^{0}$, Bastiaan S. Star ${ }^{1}$, Matijs van Meurs ${ }^{2,3}$, Robert H. Henning ${ }^{1}$, Jill Moser ${ }^{2,3}$ and Hjalmar R. Bouma ${ }^{1,4^{*}}$

\begin{abstract}
Background: Sepsis is a life-threatening condition accompanied by organ dysfunction subsequent to a dysregulated host response to infection. Up to $60 \%$ of patients with sepsis develop acute kidney injury (AKI), which is associated with a poor clinical outcome. The pathophysiology of sepsis-associated AKI (sepsis-AKI) remains incompletely understood, but mitochondria have emerged as key players in the pathogenesis. Therefore, our aim was to identify mitochondrial damage in patients with sepsis-AKl.
\end{abstract}

Methods: We conducted a clinical laboratory study using "warm" postmortem biopsies from sepsis-associated AKI patients from a university teaching hospital. Biopsies were taken from adult patients $(n=14)$ who died of sepsis with $\mathrm{AKI}$ at the intensive care unit (ICU) and control patients $(n=12)$ undergoing tumor nephrectomy. To define the mechanisms of the mitochondrial contribution to the pathogenesis of sepsis-AKl, we explored mRNA and DNA expression of mitochondrial quality mechanism pathways, DNA oxidation and mitochondrial DNA (mtDNA) integrity in renal biopsies from sepsis-AKI patients and control subjects. Next, we induced human umbilical vein endothelial cells (HUVECs) with lipopolysaccharide (LPS) for $48 \mathrm{~h}$ to mimic sepsis and validate our results in vitro.

Results: Compared to control subjects, sepsis-AKI patients had upregulated mRNA expression of oxidative damage markers, excess mitochondrial DNA damage and lower mitochondrial mass. Sepsis-AKI patients had lower mRNA expression of mitochondrial quality markers TFAM, PINK1 and PARKIN, but not of MFN2 and DRP1. Oxidative DNA damage was present in the cytosol of tubular epithelial cells in the kidney of sepsis-AKI patients, whereas it was almost absent in biopsies from control subjects. Oxidative DNA damage co-localized with both the nuclei and mitochondria. Accordingly, HUVECs induced with LPS for $48 \mathrm{~h}$ showed an increased mnSOD expression, a decreased TFAM expression and higher mtDNA damage levels.

Conclusion: Sepsis-AKI induces mitochondrial DNA damage in the human kidney, without upregulation of mitochondrial quality control mechanisms, which likely resulted in a reduction in mitochondrial mass.

Keywords: Sepsis, Acute kidney injury, Reactive oxygen species, Mitochondria

*Correspondence: h.r.bouma@umcg.nl

${ }^{1}$ Department of Clinical Pharmacy and Pharmacology, University

of Groningen, University Medical Center Groningen, P.O. Box 30.001, EB70,

9700 RB Groningen, The Netherlands

Full list of author information is available at the end of the article

\section{Introduction}

Sepsis is defined as a dysregulated host response to infection, which can lead to loss of organ homeostasis, multiple organ failure, and ultimately, death in patients [1]. Mortality and morbidity associated with sepsis and septic shock are high. In-hospital mortality rate amounts to $20-30 \%$ for sepsis and $40-60 \%$ for septic shock $[1,2]$. original author(s) and the source, provide a link to the Creative Commons licence, and indicate if changes were made. The images or other third party material in this article are included in the article's Creative Commons licence, unless indicated otherwise in a credit line to the material. If material is not included in the article's Creative Commons licence and your intended use is not permitted by statutory regulation or exceeds the permitted use, you will need to obtain permission directly from the copyright holder. To view a copy of this licence, visit http://creativecommons.org/licenses/by/4.0/. The Creative Commons Public Domain Dedication waiver (http://creativeco mmons.org/publicdomain/zero/1.0/) applies to the data made available in this article, unless otherwise stated in a credit line to the data. 
Despite extensive research, the pathophysiology of sepsis remains incompletely understood. As a result, therapeutic options directed at the molecular cause of organ dysfunction are lacking, and the current therapy is limited to source control (i.e., antibiotics, drainage) and organ support [1-4]. Up to $60 \%$ of patients with sepsis develop acute kidney injury (AKI) and sepsis is the most common cause of AKI in the intensive care unit (ICU) $[5,6]$. The occurrence of AKI in sepsis is associated with failure of other organs and increased mortality $[5,6]$. Thus, sepsisAKI constitutes a serious medical health problem.

Mitochondria have emerged as key players in the pathogenesis of sepsis-AKI [7-9]. Healthy mitochondria are essential for maintaining renal homeostasis and are important in supporting the metabolic challenge during sepsis $[2,7,8]$. Mitochondrial failure during sepsis results in renal ATP-depletion and increased levels of reactive oxygen species (ROS), which progresses into loss of cellular homeostasis and organ dysfunction [10]. Sepsis lowers ATP levels, increases biomarkers for mitochondrial dysfunction and reduces antioxidant defense, which are associated with poor survival, as demonstrated in muscle biopsies in 16 critically ill patients compared to 10 healthy, age-matched patients undergoing elective hip surgery [11]. It is known that accumulating levels of ROS during sepsis can cause damage to mitochondrial proteins and DNA in liver and heart from rats $[12,13]$, further impairing mitochondrial function and leading to a vicious circle in which ROS production continues to increase [12-14]. Conversely, biogenesis of mitochondria is associated with an increased survival of septic shock [11], and experimental models of sepsis-AKI confirm the importance of maintaining healthy mitochondria for renal recovery and survival [15-19].

To date, the precise molecular mechanisms of mitochondria in the pathogenesis of sepsis-AKI are incompletely understood, which hampers the development of a molecular targeted therapy to prevent or treat sepsisAKI and improve outcome. The high metabolic burden during sepsis leads to increased ROS production by mitochondria. We hypothesized that damage to mitochondrial DNA during sepsis causes mitochondrial dysfunction with relevance to both short-term outcome and potentially also for long-term outcome in sepsis-AKI. We therefore explored the mRNA expression of mitochondrial quality mechanism pathways and studied mitochondrial DNA (mtDNA) oxidation and integrity in renal biopsies from sepsis-AKI patients and control subjects. Next, we validated these results in vitro, by inducing human umbilical vein endothelial cells (HUVECs) with lipopolysaccharide (LPS) for $48 \mathrm{~h}$ to mimic sepsis.

\section{Material and methods}

\section{Patients}

We collected postmortem renal biopsies from patients as quickly as possible after death [24-150-min postmortem] from fourteen patients who died of sepsis with acute kidney injury at the ICU of the University Medical Center Groningen (UMCG). The biopsy was taken from the renal cortex, and once removed from the patient, the biopsies were immediately snap frozen using liquid nitrogen and stored in the $-80{ }^{\circ} \mathrm{C}$ until analysis. No in vitro perfusion took place. Due to the rapid sampling time and immediate freezing, we eliminated unwanted tissue necrosis and autolysis, which would disturb the analysis. Patients were defined as having septic shock according to the internal sepsis definitions, comprising sepsis with atrial hypotension despite adequate fluid resuscitation [20], while AKI was classified according to the RIFLE criteria [21]. Severity of illness was defined upon admission to the ICU using the Acute Physiology and Chronic Health Evaluation (APACHE) IV score and the Simplified Acute Physiology Score (SAPS) II score [22, 23]. Informed written consent for performing biopsies was obtained during the family meeting, before or just after death. In control subjects, following preoperative consent, nonseptic kidney biopsies were obtained from twelve patients who underwent complete nephrectomy due to renal cell carcinoma. In this procedure, a healthy section of the kidney cortex was taken, as far away as possible from the carcinoma. Nephrectomy biopsies were analyzed by a pathologist and considered to be normal healthy controls. Additional details of the collection of kidney biopsies are described elsewhere [24]. Both septic patients and controls were 18 years or older. Patients with preexisting chronic kidney disease (CKD), active autoimmune disorders with renal involvement and treatment with immune-suppressive medication were excluded from this study. The Medical Ethics Review Committee (METC) of the UMCG reviewed and approved this study (METC 2011/372). Patient characteristics and clinical and laboratory details can be found in Table 1 .

\section{Cells}

Human umbilical vein endothelial cells (HUVECs) and medium were obtained from the UMCG Endothelial Cell Facility. Briefly, primary isolates of umbilical cords were mixed and subsequently cultured on HUVEC culture medium, consisting of RPMI 1640 (Lonza, Breda, Netherlands) supplemented with $20 \%$ heat-inactivated fetal calf serum (ThermoFisher, Waltham, MA), 2 mM l-glutamine (Life Technologies, Carlsbad, CA), $5 \mathrm{U} / \mathrm{ml}$ heparin (Leo 
Table 1 Patient characteristics

\begin{tabular}{|c|c|c|}
\hline & Control $(n=12)$ & Sepsis-AKI $(n=14)$ \\
\hline Mean age (years) & $62(20-79)$ & $76(53-85)$ \\
\hline Sex (male:female) & $5: 7$ & $11: 3$ \\
\hline \multicolumn{3}{|l|}{ Comorbidities/medical history $(n)$} \\
\hline Hypertension & 3 & 6 \\
\hline Diabetes mellitus & 1 & 1 \\
\hline COPD or asthma & 4 & 2 \\
\hline Coronary artery disease & 1 & 5 \\
\hline Renal disease & 0 & 0 \\
\hline Auto-immune disease & 0 & 1 \\
\hline Neoplasms (extra-renal) & 4 & 1 \\
\hline RIFLE stage $(n)$ & N/A & \\
\hline Risk & & 0 \\
\hline Injury & & 6 \\
\hline Failure & & 8 \\
\hline Lost renal function & & 0 \\
\hline End-stage kidney failure & & 0 \\
\hline Need for RRT in ICU: yes/no & N/A & $5 / 14$ \\
\hline Serum creatinine at admission $(\mu \mathrm{mol} / \mathrm{L})$ & N/A & $135(81-355)$ \\
\hline Serum creatinine before biopsy ( $\mu \mathrm{mol} / \mathrm{L})$ & $73(58-114)$ & $156(73-401)$ \\
\hline APACHE IV score & N/A & $97(50-175)$ \\
\hline SAPS II score & N/A & $65(35-88)$ \\
\hline Sepsis focus & N/A & \\
\hline Lower respiratory tract & & 5 \\
\hline Skin/soft tissue & & 2 \\
\hline Intra-abdominal (Mesenteric ischemia, necrotizing pancreatitis) & & 6 \\
\hline Endovascular (endocarditis) & & 1 \\
\hline
\end{tabular}

Data are presented as median with upper and lower range. N/A not applicable, RRT renal replacement therapy, ICU intensive care unit, APACHE Acute Physiology and Chronic Health Evaluation, SAPS Simplified Acute Physiology Score

Pharmaceutical Products, The Netherlands), 1\% Penicillin/Streptomycin (Sigma-Aldrich, St. Louis, MI) and $50 \mu \mathrm{g} / \mathrm{ml}$ EC growth factor supplement from (SigmaAldrich). Cells were plated in 6-well culture plates (Corning, St. Louis, MI), and at $80 \%$ confluency cells were stimulated with $10 \mu \mathrm{g} / \mathrm{ml}$ lipopolysaccharide (LPS) E. coli 0111:B4 (Sigma-Aldrich) for $48 \mathrm{~h}$.

\section{DNA isolation}

Total DNA was isolated to perform a polymerase chain reaction (PCR) and determine mitochondrial DNA damage. DNA was isolated from renal biopsies of eight controls subjects and twelve sepsis-AKI patients. First, sections of $5 \mu \mathrm{m}$ thickness were cut from the renal biopsies. Samples were pretreated with $500 \mu \mathrm{L}$ collagenase V (300 U/mL; Sigma-Aldrich, Darmstadt, Germany), incubated at $37^{\circ} \mathrm{C}$ for $3 \mathrm{~h}$ and vortexed every $30 \mathrm{~min}$. Subsequently, $500 \mu \mathrm{L}$ RPMI (ThermoFisher, Paisly, UK) was added, followed by centrifugation for $10 \mathrm{~min}$ at 20,000 $\mathrm{G}$ at room temperature. Next, Rapid Sample Concentrator
(RSC) blood DNA kit (Promega, Madison, USA) was used to isolate DNA from the pellet using Maxwell 16 MDx AS3000 (Promega), according to the manufacturer's protocol. DNA from HUVECs was isolated with Nucleospin DNA kit (MACHEREY-NAGEL, GmbH \& Co. KG, Germany), according to manufacturer's protocol.

\section{Quantification of mitochondrial mass and DNA damage}

Mitochondrial copy number, indicative of mitochondrial mass, and mitochondrial DNA damage were determined using quantitative polymerase chain reaction (qPCR). Oligonucleotide primers (Sigma-Aldrich; Table 2) were designed using Clone Manager 9 software and validated by assessing the efficiency, melting- and temperature curves using CFX384- Real-Time system (Biorad, California, USA). Amplification of the DNA was performed using the following thermal profile: $95{ }^{\circ} \mathrm{C}$ for $2 \mathrm{~min}$, followed by 40 cycles of $95{ }^{\circ} \mathrm{C}$ for $15 \mathrm{~s}, 60^{\circ} \mathrm{C}$ for $30 \mathrm{~s}$ and $72{ }^{\circ} \mathrm{C}$ for $30 \mathrm{~s}$. All reactions were carried out in duplicate, and the obtained threshold cycle $(\mathrm{Ct})$ values were averaged. MtDNA copy number was calculated using the 
Table 2 List of primers used for quantification of mRNA and DNA expression levels by qPCR and RT-qPCR

\begin{tabular}{lll}
\hline Gene & Primer sequence \\
\hline ND1, ETC complex 1 & Forward: & TGGCTCCTTTAACCTCTCCA \\
ND4, ETC complex 1 & Reverse: & GGTTCGGTTGGTCTCTGCTA \\
& Forward: & GGCGGCTATGGTATAATACG \\
ND6, ETC complex 1 & Reverse: & GTAGGCAGATGGAGCTTGTT \\
& Forward: & TGATTGTTAGCGGTGGGTC \\
COX1, ETC complex 4 & Reverse: & CCTCAATAGCCATCGCTGTA \\
& Forward: & CTAACAGACCGCAACCTCAA \\
Cytochrome b, ETC complex 3 & Foverse: & CCGAAGCCTGGTAGGATAA \\
& Reverse: & TTCCTAGCCATGCACTACTC \\
D-loop, regulative region & Forward: & AACCTACCCACCCTTAACAG \\
B2M & Reverse: & CACTCTTGTGCGGGATATTG \\
& Forward: & CTGGGTAGCTCTAAACAATGT \\
& ATTCA \\
& Reverse: & CATGTACTAACAAATGTCTAA \\
& & AATGGT \\
\hline
\end{tabular}

ETC electron transport chain

average levels of the mitochondrial genes: NADH dehydrogenase 1 (ND1), NADH dehydrogenase 4 (ND4), NADH dehydrogenase 6 (ND6), Cytochrome C Oxidase I (COX1), Cytochrome B (CYTB) and D-loop, divided by the amount of nuclear housekeeping gene Beta 2-microglobulin (B2M), using the $2-\Delta \Delta \mathrm{Ct}$ method.

Mitochondrial DNA damage was assessed by qPCR for determination of a short ( $200 \mathrm{bp})$ mtDNA part and long-range PCR, for determination of a long (10 kb) mtDNA part. First, the relative amount of each mitochondrial gene was quantified by qPCR and divided by the amount of nuclear housekeeping gene $B 2 M$, using the $2-\Delta \Delta C t$ method. Next, a long-range PCR was performed using the TaKaRa LA Taq DNA polymerase kit (Takara Bio, Kusatsu, Japan) to amplify a 10-kb mtDNA template, stretching from the ND5 to ND1 gene, thereby comprising more than two-third of the mitochondrial genome. A short mtDNA fragment of $222 \mathrm{bp}$ was amplified by qPCR to serve as reference (Table 3 ). The long fragment was amplified with T100 Thermal Cycler (Biorad, California, USA), using the following thermal profile: $94{ }^{\circ} \mathrm{C}$ for $1 \mathrm{~min}$, followed by 18 cycles of $15 \mathrm{~s}$ at $94{ }^{\circ} \mathrm{C}$ and $12 \mathrm{~min}$ at $64{ }^{\circ} \mathrm{C}$, and ending with $10 \mathrm{~min}$ at $72{ }^{\circ} \mathrm{C}$. The short fragment was amplified using the following thermal profile: $95^{\circ} \mathrm{C}$ for $2 \mathrm{~min}$, followed by 40 cycles of $95^{\circ} \mathrm{C}$ for $15 \mathrm{~s}$ and $60^{\circ} \mathrm{C}$ for $30 \mathrm{~s}$. Both PCR products were separated and visualized on a $1 \%$ agarose gel (45 min, $100 \mathrm{~V}$ ), and their intensity was analyzed using ImageJ [25]. The ratio of the short to long fragment was calculated to quantify mtDNA damage. Due to limited sample
Table 3 List of primers used for amplification of mitochondrial DNA with long-range PCR and QPCR

\begin{tabular}{ll}
\hline Primer & Primer sequence \\
\hline $\begin{array}{l}\text { Forward long fragment mtDNA } \\
(10 \mathrm{~kb})\end{array}$ & TCTAAGCCTCCTTATTCGAGCCGA \\
$\begin{array}{l}\text { Forward Short fragment mtDNA } \\
(222 \mathrm{bp})\end{array}$ & CCCCACAAACCCCATTACTAAACCCA \\
$\begin{array}{l}\text { Reverse primer mtDNA (short and } \\
\text { long) }\end{array}$ & TTTCATCATGCGGAGATGTTGGATGG \\
\hline $\begin{array}{l}\text { mtDNA mitochondrial DNA } \\
\end{array}$
\end{tabular}

material, DNA from six control subjects and twelve sepsis-AKI patients was used for long-range PCR, whereas material from seven control subjects and twelve sepsisAKI patients was used for $\mathrm{qPCR}$.

\section{RNA isolation and quantification of gene expression}

First, total RNA was isolated from twelve control subjects and twelve sepsis-AKI patients for reverse transcription by quantitative polymerase chain reaction (RT-qPCR). RNA was isolated from $20 \times 5 \mu \mathrm{m}$ kidney cryosections using the RNeasy Mini Plus Kit (Qiagen, Leusden, The Netherlands), according to the manufacturer's protocol. RNA integrity was determined by gel electrophoresis and consistently found intact. RNA yield and purity were measured by an ND-1000 UV-Vis spectrophotometer (NanoDrop Technologies, Rockland, DE). cDNA was synthesized as previously described [26]. RNA from HUVECs was isolated using Nucleospin RNA kit (MACHEREY-NAGEL). Cells were pretreated with TRIzol, followed by RNA isolation according to manufacturer's protocol. Next, oligonucleotide primers (Sigma-Aldrich; Table 4) were designed using Clone Manager 9 software and validated by assessing the efficiency, melting- and temperature curve using RT-qPCR. RT-qPCR amplification was performed using the following thermal profile: $95^{\circ} \mathrm{C}$ for $2 \mathrm{~min}$, followed by 40 cycles of $95^{\circ} \mathrm{C}$ for $15 \mathrm{~s}, 60^{\circ} \mathrm{C}$ for $30 \mathrm{~s}$ and $72{ }^{\circ} \mathrm{C} 30 \mathrm{~s}$. Reactions were carried out in duplicate, and the obtained $\mathrm{Ct}$ values were averaged. Gene expression (mRNA) was normalized using $\beta$-actin as a housekeeping gene, and $2-\Delta \Delta \mathrm{Ct}$ was used to obtain relative quantity.

\section{Immunohistochemical analysis}

DNA oxidation was assessed by immunohistochemical analysis of 8-oxoguanine (8-oxoG) on formalin-fixed paraffin-embedded kidney sections. Therefore, sections were deparaffinized in xylene and rehydrated in graded ethanol series (70-100\%) and distilled water. After deparaffination, heat-induced epitope retrieval was performed using citrate buffer $(\mathrm{pH} \mathrm{6)}$ antigen retrieval. 
Table 4 List of primers for quantification of mRNA expression of mitochondrial quality mechanisms, mitochondrial complexes and oxidation pathways by RT-qPCR

\begin{tabular}{|c|c|c|c|}
\hline \multirow{2}{*}{$\frac{\text { Gene }}{\text { PINK1 }}$} & \multicolumn{2}{|c|}{ Primer sequence } & \multirow{2}{*}{$\begin{array}{l}\text { Process } \\
\text { Mitophagy }\end{array}$} \\
\hline & Forward: & GACGCTGTTCCTCGTTATGA & \\
\hline & Reverse: & TCCAGCTCCACAAGGATGTT & \\
\hline \multirow[t]{2}{*}{ PARKIN } & Forward: & GACCCTCAACTTGGCTACTC & Mitophagy \\
\hline & Reverse: & CTTCGCAGGTGACTTTCCTC & \\
\hline \multirow[t]{2}{*}{ MFN2 } & Forward: & CCGCCACATAGAGGAAGGAC & Fusion \\
\hline & Reverse: & CGCACAGACACAGGAAGGAG & \\
\hline \multirow[t]{2}{*}{ DRP1 } & Forward: & AAGCTGCTGCCATAGTCCTC & Fission \\
\hline & Reverse: & ACCACAGCCATGTCAGTGTC & \\
\hline \multirow[t]{2}{*}{ NRF2 } & Forward: & GCTACTAATCAGGCTCAGTC & Mitochondrial biogenesis \\
\hline & Reverse: & GTAGTCTCAACCAGCTTGTC & \\
\hline \multirow[t]{2}{*}{ TFAM } & Forward: & CATGGACTTCTGCCAGCATA & Mitochondrial biogenesis \\
\hline & Reverse: & AGAACACCGTGGCTTCTACA & \\
\hline \multirow[t]{2}{*}{ mnSOD } & Forward: & ACGCGGCCTACGTGAACAAC & Antioxidant enzyme \\
\hline & Reverse: & CAACAGATGCAGCCGTCAGC & \\
\hline \multirow[t]{2}{*}{ OGG1 } & Forward: & GTGTGCGACTGCTGCGACAA & mtDNA damage repair (excision of 8-oxoguanine) \\
\hline & Reverse: & CTGGATGAGCCGAGGTCCAA & \\
\hline \multirow[t]{2}{*}{ HIFla } & Forward: & TGAGGGGACAGGAGGATCAG & Master regulator of cellular and systemic homeo- \\
\hline & Reverse: & CACGCGGAGAAGAGAAGGAA & \\
\hline \multirow[t]{2}{*}{ SIRT1 } & Forward: & ATGCTGGCCTAATAGAGTGG & Regulates epigenetic gene silencing, biogenese \\
\hline & Reverse: & TCTGGAACATCAGGCTCATC & and antioxidant mechanisms \\
\hline \multirow[t]{2}{*}{ NGAL } & Forward: & GGTGAGCACCAACTACAACC & Early biomarker of acute kidney injury \\
\hline & Reverse: & GCCCAGAGATTTGGAGAAGC & \\
\hline \multirow[t]{2}{*}{ NDUFA1 } & Forward; & ACTGGCTACTGCGTACATCC & ETC complex 1 (nDNA) \\
\hline & Reverse: & AGATGCGCCTATCTCTTTCC & \\
\hline \multirow[t]{2}{*}{$\operatorname{cox} 5 b$} & Forward: & CATTGGCTCCTTCTCCCATA & ETC complex 4 (nDNA) \\
\hline & Reverse: & CATACCAGGTGGTCCCATTC & \\
\hline \multirow[t]{2}{*}{ B-actin } & Forward: & AGGATGCAGAAGGAGATCAC & Housekeeping gene \\
\hline & Reverse: & AGTCATAGTCCGCCTAGAAG & \\
\hline
\end{tabular}

mtDNA mitochondrial DNA, ETC electron transport chain, $n D N A$ nuclear DNA

Endogenous peroxidase activity was blocked by incubating the slides with $3 \%$ hydrogen peroxide. After washing, the slides were incubated with anti-human 8-oxoG Antibody, (Abcam, Cambridge, UK) diluted 1:400 in antibody solution (5\% fetal calf serum in PBS) for $1 \mathrm{~h}$ at room temperature. After washing, slides were incubated with rabbit anti-mouse IgG secondary antibody (Southern Biotech, Birmingham, USA) diluted 1:100 in antibody solution with $2 \%$ normal human serum (NHS) for $45 \mathrm{~min}$ at room temperature. Slides were washed and incubated with anti-rabbit horse radish peroxidase-labeled antibody (EnVision kit, DAKO Cytomation, Glostrup, Denmark). Peroxidase activity was detected using 3-amino-9-ethylcarbazole (AEC) complex, and the sections were subsequently counterstained with Mayer's hematoxylin (Merck, Darmstadt, Germany) before mounting in Aquatex mounting agent (Merck). 8-oxoG staining was visualized with a Leica DCF295 color camera (Leica,
Heerbrugg, Switzerland), and images taken with the Leica software application suite (LAS version 4, Leica).

\section{Immunofluorescent analysis}

Co-localization of DNA oxidation and mitochondria was assessed by immunofluorescent analysis of Translocase Of Outer Mitochondrial Membrane (TOM20) (mitochondrial immunolabeling) and 8-oxoG on kidney cryosections $(9 \mu \mathrm{m})$. In short, the slides were air-dried, fixated with ice-cold acetone for $10 \mathrm{~min}$, washed with PBS and permeabilized with $0.25 \%$ Triton-X-100 for $10 \mathrm{~min}$. Then, sections were incubated for $1 \mathrm{~h}$ at room temperature with the primary 8-oxoG antibody (Novus Biologicals, Abingdon, Oxon), diluted 1:75 in 1\% bovine serum albumin (BSA) in PBS, washed with PBS and incubated for 30 min with Donkey anti-Goat secondary antibody (ThermoFisher), diluted $1: 100$ in $1 \%$ PBS/BSA. Next, slides were incubated for $1 \mathrm{~h}$ at room temperature with 
TOM20 primary antibody (Santa Cruz, Dallas, USA), diluted 1:20 in 1\% PBS/BSA, followed by washing with PBS and incubation for 30 min with Donkey anti-Rabbit IgG secondary antibody (ThermoFisher), diluted 1:100 in $1 \%$ PBS/BSA. Slides were mounted in Vectashield with DAPI (Vector Laboratories Inc., Burlingame, CA, USA) and visualized with a Leica DM2000 microscope (Leica, Amsterdam, Netherlands). Co-localization was identified using ImageJ software.

\section{Statistical analysis and data presentation}

Statistical analysis was performed with IBM SPSS 23.0 for Windows (IBM Corp., Armonk, N.Y., USA) and GraphPad Prism Software version 7.02 (GraphPad Prism software Inc., San Diego, CA, USA). Two-tailed MannWhitney $U$ tests were used to calculate statistical differences between groups (using GraphPad Prism software), whereas correlations between selected groups were assessed by Spearman's Rho tests in IBM SPSS. $P<0.05$ was considered significant different. Data are expressed as median with upper and lower ranges. Figures were made with GraphPad Prism (GraphPad Prism software Inc.), bars represent the median and each dot represents an individual.

\section{Results}

\section{Study population}

Renal biopsies from fourteen patients with sepsis-AKI and twelve control subjects were examined. Six sepsisAKI patients had an intra-abdominal infection, five patients suffered from a lower respiratory tract infection, two patients had a skin/soft tissue infection and one patient suffered from endocarditis. The median age of patients with sepsis-AKI was 76 (range 53-85) years, and for control subjects the median age was 62 (range 20-79) (Table 1). The male-to-female ratio was 11:3 and 5:7 for sepsis-AKI and control subjects, respectively. Six sepsisAKI patients were categorized in the Injury stage of the RIFLE criteria and eight in the Failure stage. Five patients needed renal replacement therapy in the ICU. Clinical characteristics are listed in Table 1, and serum creatinine before nephrectomy in control subjects or before the biopsy was taken in sepsis-AKI patients is shown in Fig. 1.

\section{Sepsis-AKI is associated with renal oxidative stress}

To explore whether sepsis-AKI leads to oxidation of DNA, we performed an 8-oxoG staining and quantified the expression of the base-excision repair enzyme 8-oxoguanine DNA glycosylase (OGG1) in kidney biopsy material. 8-oxoG staining, a mutagenic base byproduct that occurs as a result of exposure to reactive oxygen species, was present in some of the tubular epithelial cells of all

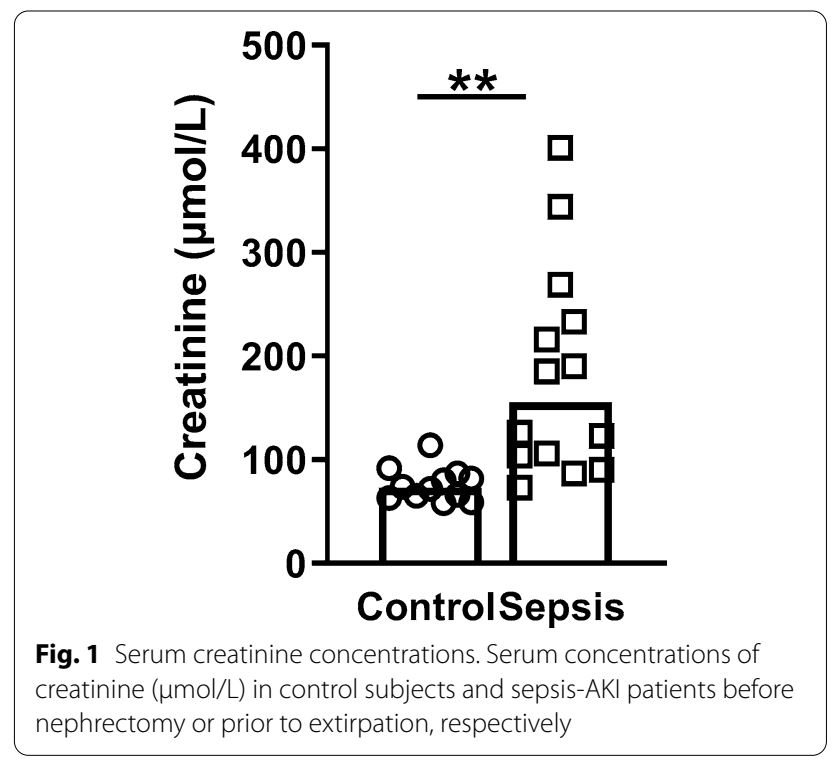

sepsis-AKI patients, but almost absent in biopsies from control subjects (Fig. 2a-d). Expression of OGG1, the primary enzyme responsible for the excision of 8-oxoG, was downregulated in patients with sepsis $(p<0.005$; Fig. 2e). Fluorescent staining of the mitochondrial marker TOM20 and 8-oxoG demonstrated their colocalization, implicating oxidation of the mitochondrial DNA (Fig. 2j, o).

To confirm the presence of kidney damage in sepsisAKI patients, we quantified mRNA expression of neutrophil gelatinase-associated lipocalin (NGAL), a marker for kidney damage and oxidative stress [26]. Septic patients showed a significantly upregulation of NGAL $(p<0.001$; Fig. 3a, b). In addition, sepsis-AKI patients showed an increased expression of hypoxia-inducible factor 1-alpha $(H I F 1 \alpha)$, the master oxygen sensor within cells and manganese superoxide dismutase ( $m n S O D)$, a key antioxidant enzyme, suggesting an active response to oxidative stress (both $p<0.001$; Fig. 3c, d). mnSOD positively correlated with NGAL and HIFo $(R=0.858$ and $R=0.921$, respectively, both $p<0.001)$. In contrast, sepsis-AKI patients had lowered mRNA expression of Sirtuin 1 (SIRT1), involved in inhibiting oxidative stress and in biogenesis, as compared to control subjects $(p<0.01$; Fig. 3 e), while NRF2 important in regulation of antioxidant protein expression was not different between both groups (Fig. 3f). Also in HUVECs the mnSOD expression was significantly increased after $48 \mathrm{~h}$ of LPS induction compared to controls $(p<0.001$, Fig $4 a)$, while NRF2 was not different (Fig. 4b). Taken together, patients with sepsisAKI likely display increased levels of oxidative stress, as demonstrated by increased levels of 8-oxoG in tubular cells and increased mRNA expression of oxidative stress defense pathways. 

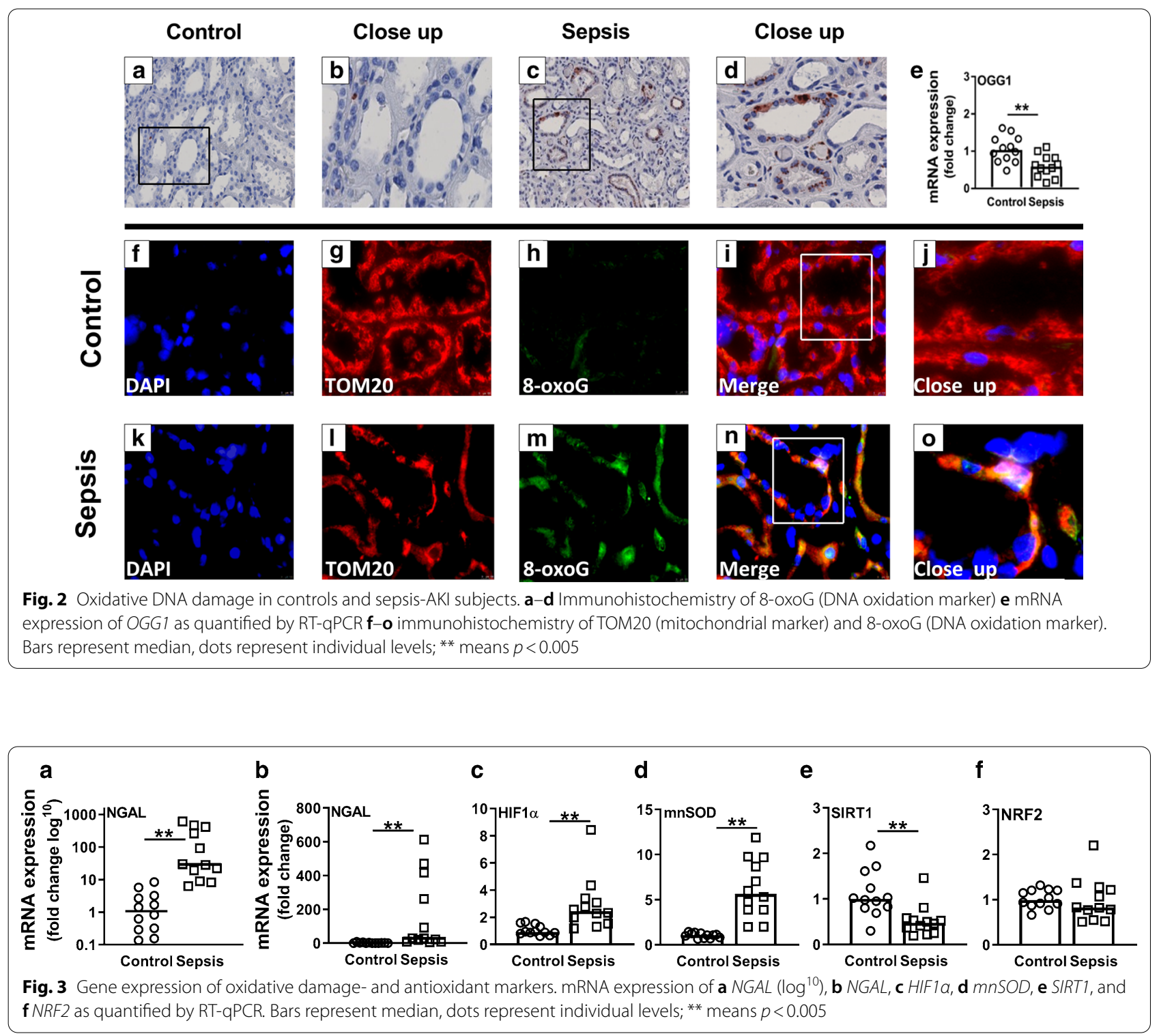

Sepsis-AKI is associated with mitochondrial DNA damage in the kidney

The integrity of mtDNA is critical to maintain normal mitochondrial function [27]. To investigate whether sepsis-AKI alters the integrity of mtDNA, we measured mtDNA damage by long-range PCR and quantified the ratio between a long and short mtDNA fragment, with higher ratios denoting more mtDNA damage (Fig. 5a). Kidney mtDNA damage was higher in sepsis-AKI patients as compared to patients without sepsis-AKI $(p<0.01$, Fig. $5 b)$. Levels of mtDNA damage positively correlated with expression of $m n S O D$ and HIF1 $\alpha$, markers for oxidative stress, and renal damage marker NGAL ( $R=0.77, R=0.68$ and $R=0.89$, respectively, all $p<0.01)$ and negatively correlated with base-excision repair enzyme OGG1 and biogenesis marker mitochondrial transcription factor A (TFAM) $(R=-0.51$ and $R=-0.65$, respectively, both $p<0.05)$. However, mtDNA damage did not correlate with the severity of critical illness as defined by the APACHE IV and SAPSII scores. Furthermore, sepsis-AKI patients had lower DNA levels of mitochondrial genes $N D 6$, and D-loop, whereas DNA levels of $N D 1, N D 4, C O X 1$ and $C Y T B$ were not different between control subjects and patients with sepsis-AKI, probably due to the small sample size and thus a type 2 error (Fig. 6). Next, we explored the mtDNA damage in 48-h LPS-induced HUVECs. In keeping, we found an increase in mtDNA damage after $48 \mathrm{~h}$ of LPS induction (Fig. 4g). Collectively, these findings show that sepsis is associated with mtDNA damage. 

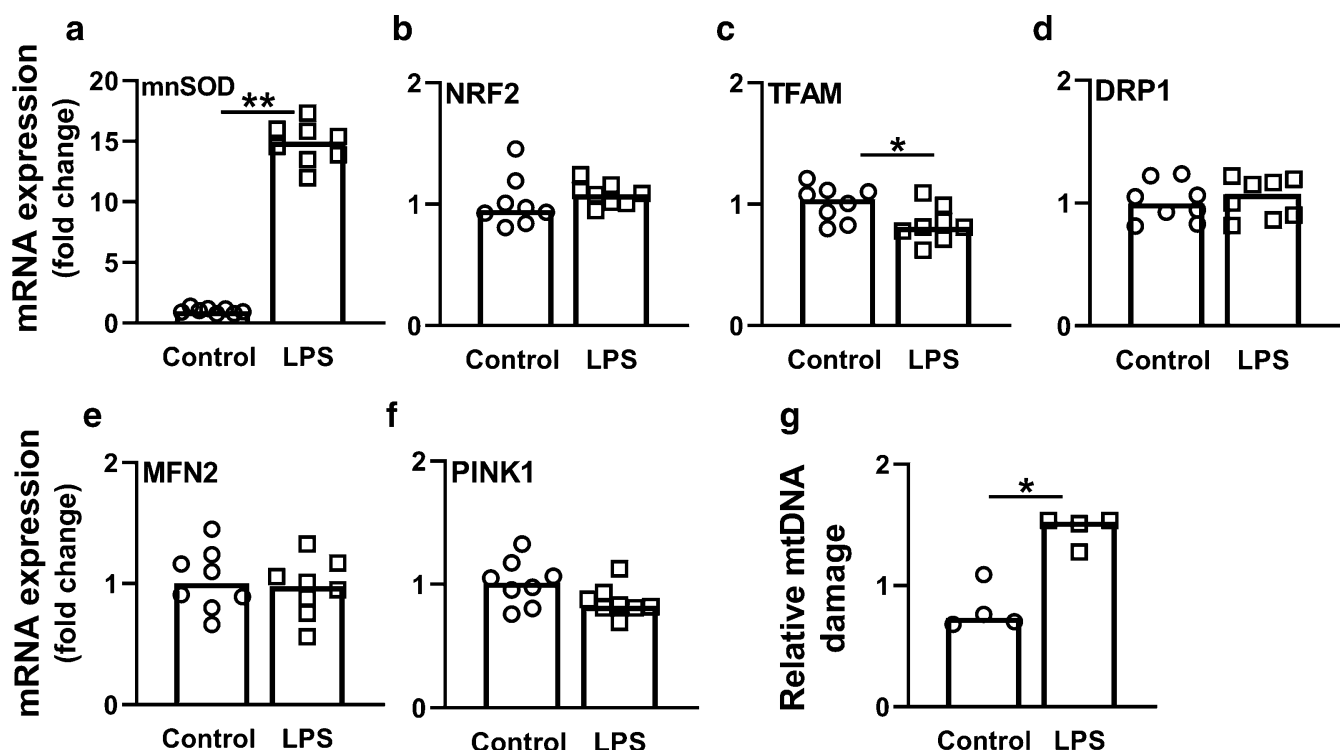

Fig. 4 Changes in mitochondrial biogenesis, fusion, fission and mitophagy after 48-h LPS induction in HUVECs. Cells were induced with $10 \mu \mathrm{g} /$ $\mathrm{mL}$ LPS for $48 \mathrm{~h}$. mRNA expression of a mnSOD, b NRF2, c TFAM, $\mathbf{d}$ DRP1, e MFN2, and $\mathbf{f}$ PINK1; $\mathbf{g}$ Relative mtDNA damage levels of control and LPS-induced HUVECs. Bars represent median, dots represent individual levels; ${ }^{*}$ means $p<0.05$ and ${ }^{* *} p<0.005$

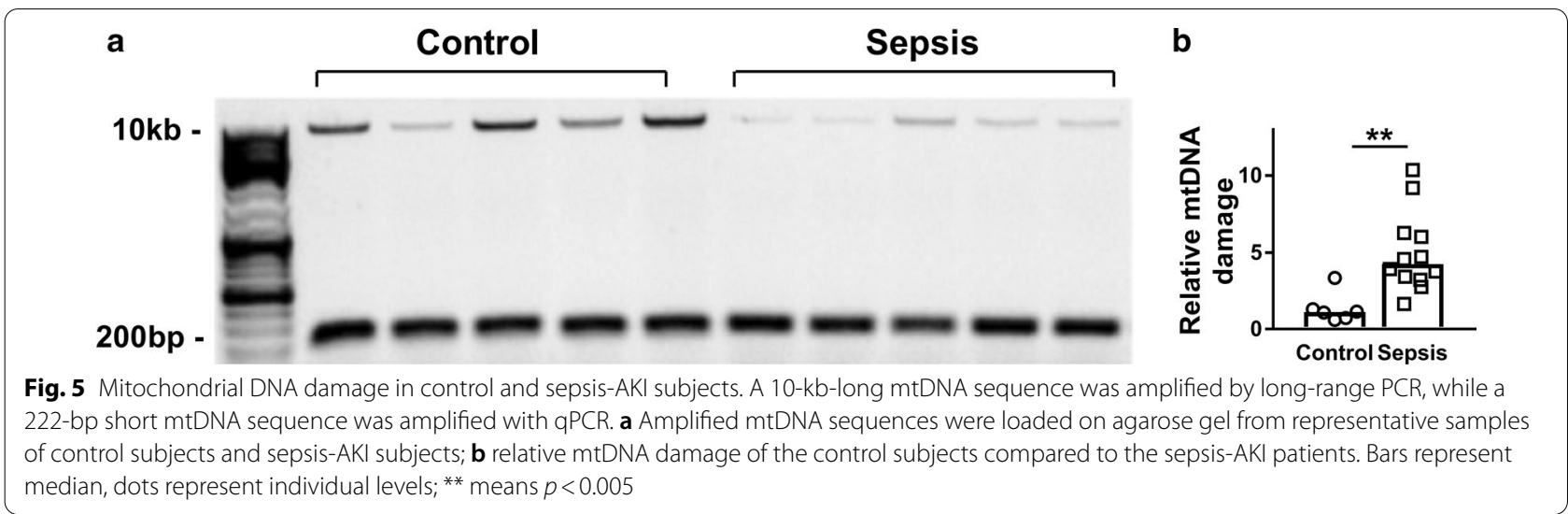

\section{Mitochondrial quality control does not compensate for mtDNA damage}

To assess mitochondrial quality control, which is important to maintain a healthy mitochondrial pool and consist of biogenesis, mitophagy, fission and fusion [28], we measured mRNA expression of genes involved in these processes. Expression of the biogenesis marker TFAM was lower in sepsis-AKI patients than in control subjects $(p<0.01$; Fig. 7a). Although sepsis-AKI led to reduced mtDNA levels and integrity, it did not affect mRNA expression of mitochondrial genes encoding key components of the mitochondrial electron transport chain complexes (i.e., ND1, ND4, COX1, CYTB, COX5b and NDUFA1) (Fig. 8). Further, sepsis-AKI did not affect mRNA expression of the mitochondrial fusion and fission markers mitofusin 2 (MFN2) and dynamin-related protein 1 (DRP1), respectively (Fig. 7b, c). As expected, however, MFN2 and DRP1 did correlate with each other $(R=0.58, p<0.01)$. Sepsis-AKI patients had lower mRNA expression of PTEN-induced putative kinase 1 (PINK1) and PARKIN, key components in regulating mitophagy and therefore important in the removal of unhealthy mitochondria, as compared to control subjects $(p<0.05$ and $p<0.01$, respectively; Fig. $7 \mathrm{~d}$, e). Expression of PINK1 correlated with PARKIN expression $(R=0.56, p<0.01)$. Accordingly, 48-h LPS induction in HUVECS caused a decrease in TFAM mRNA expression, but did not change MFN2, DRP1 or PINK1 expression (Fig. 4c-f). Collectively, these data imply that sepsis-AKI patients 


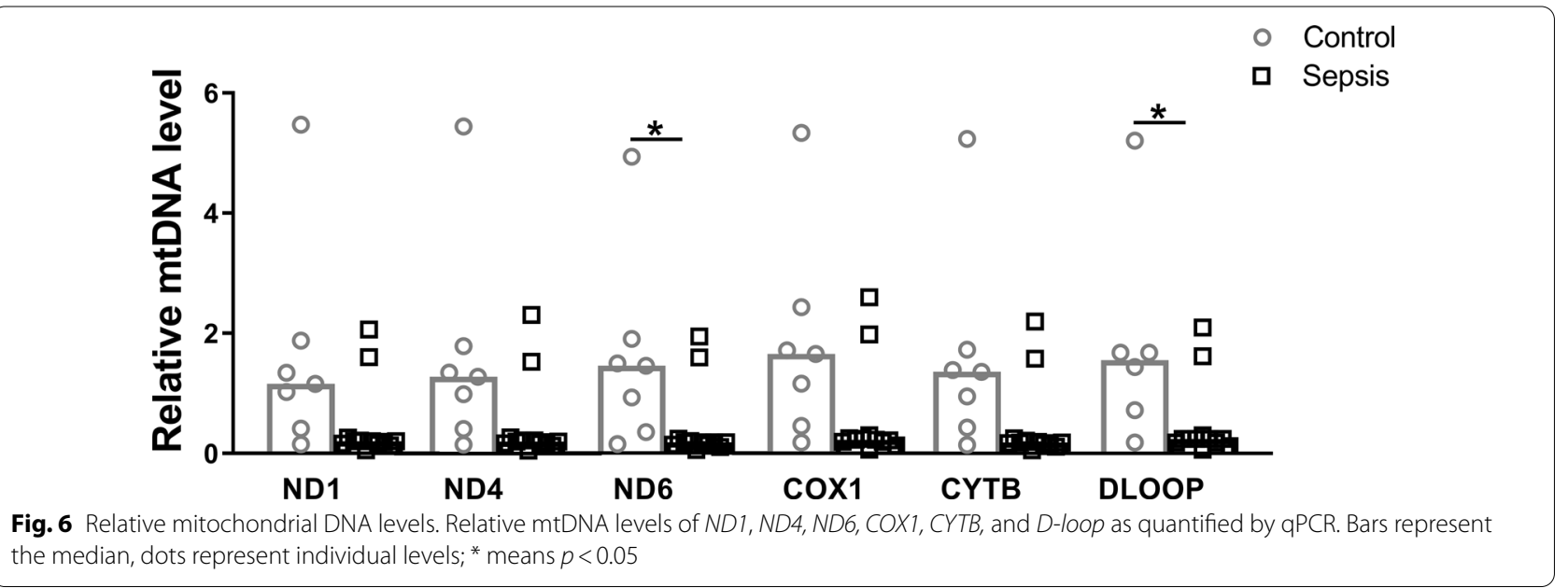

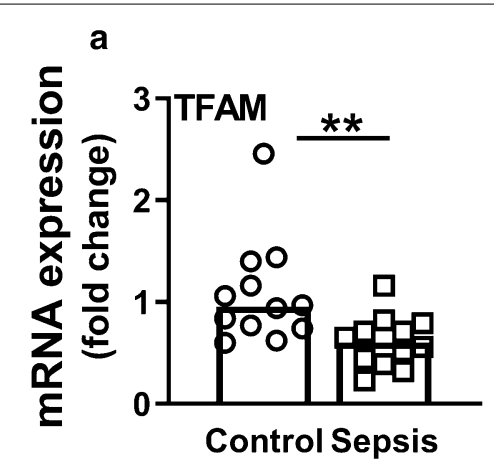

b

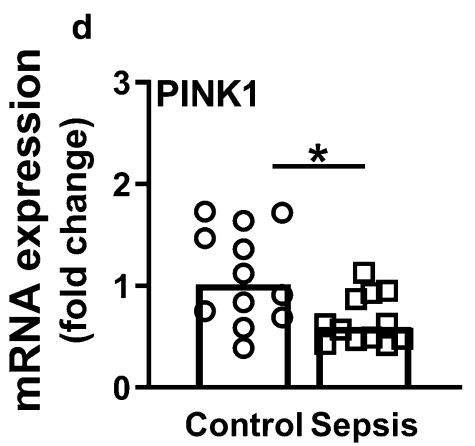

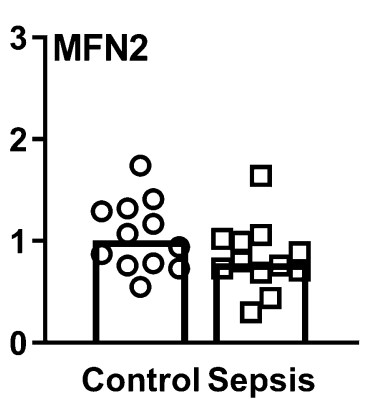

e

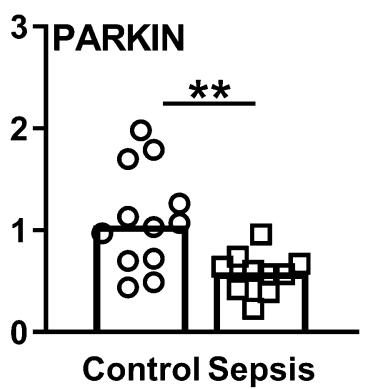

C

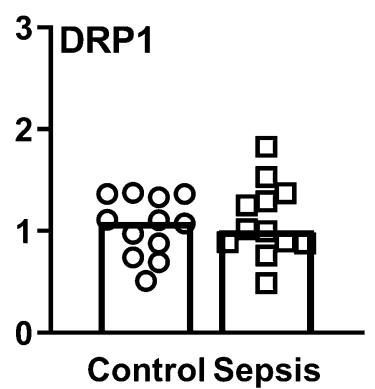

f

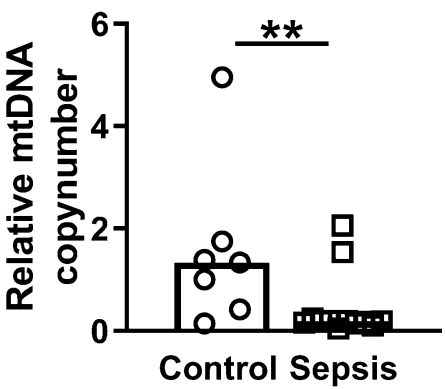

Fig. 7 Changes in mitochondrial biogenesis, fusion, fission, mitophagy and copy number in response to sepsis-AKI. mRNA expression of a TFAM, b MFN2, c DRP1, d PINK1, and e PARKIN as quantified by RT-qPCR; f mtDNA levels were quantified by RT-qPCR to calculate the mitochondrial copy number. Bars represent median, dots represent individual levels; ${ }^{* * *}$ means $p<0.05 / 0.005 ;$ mtDNA mitochondrial DNA

and LPS-induced HUVECs did not have a compensatory increase in mitochondrial quality control mechanisms.

\section{Sepsis-AKI causes a decrease in mitochondrial mass}

Based on the increase in antioxidant markers and decrease in mitochondrial biogenesis markers, we hypothesized that patients with sepsis-AKI had a reduction in the mitochondrial mass, due to increased oxidative stress while having reduced mitochondrial quality control. To estimate the mitochondrial mass, we determined the mitochondrial copy number by calculating the ratio between the expression of mitochondrial genes and the nuclear housekeeping gene $B 2 M$. In keeping with the elevated mitochondrial DNA damage ratio, mitochondrial DNA levels were reduced in sepsis-AKI compared to control subjects, denoting a decrease in 
mitochondrial mass $(p<0.05$; Fig. $7 \mathrm{f})$. Hence, sepsis-AKI shows increased mitochondrial DNA damage ratio, a decreased mitochondrial mass, in the absence of compensation of mitochondrial quality control markers.

\section{Discussion}

Sepsis leads to increased levels of ROS, which is in part due to the overwhelming immune response to facilitate bacterial killing $[1,27,29]$. In turn, ROS can cause collateral damage by oxidizing proteins, lipids and DNA [12, 13]. Subsequent damage to mtDNA can impair mitochondrial function and further increase ROS generation $[27,29]$. Whether this process underlies the pathophysiology in sepsis-AKI was not yet known. Here, we demonstrate that sepsis-AKI patients have an upregulated mRNA expression of markers important in the renal oxidative stress response, leading to higher levels of mtDNA oxidation, mtDNA damage and a reduced number of mitochondria in the kidney. Despite the mitochondrial damage, we did not find evidence of compensatory upregulation of mitochondrial quality control mechanisms, which further substantiates mitochondrial dysfunction in sepsis-AKI. Together, these data demonstrate key mechanisms leading to mitochondrial failure in the pathophysiology of sepsis-AKI.

The way cells deal with ROS under inflammatory circumstances is important for the distinction between survival, long-term complications, or mortality of patients

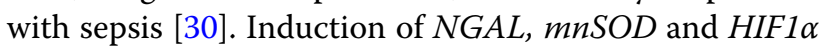
is indicative of renal oxidative stress and injury [31-33]. One of the first markers of renal injury is upregulation of NGAL expression [34], as demonstrated in our biopsies derived from patients with sepsis-AKI. Increased NGAL expression is regulated by ROS to suppress bacterial growth and modulate the inflammatory response [31]. In turn, NGAL activates antioxidant defense mechanisms, leading to the upregulation of $m n S O D$, as demonstrated in vitro [31]. Accordingly, we found a positive correlation between NGAL expression and mnSOD expression in the renal biopsies. The importance of upregulated $m n S O D$ in sepsis is confirmed in mouse models of sepsis (i.e., lipopolysaccharide [LPS] injection and cecal ligature and puncture [CLP]), where higher $m n S O D$ expression prevented ATP depletion and subsequent mortality [33, 35, 36]. Similarly, we found an increased gene expression of $m n S O D$ expression in patients with sepsis-AKI as compared to control subjects. Upregulation of HIF1 $\alpha$ switches mitochondrial aerobic respiration to glycolysis metabolism, thereby bypassing the dysfunctional ROSproducing mitochondria and lowering oxidative stress [32]. Higher HIF1 $\alpha$ expression levels were detected in whole blood cells from patients with septic shock [37], in line with the increased expression in the kidney as demonstrated here in sepsis-AKI. In contrast to NGAL, $m n S O D$ and $H I F 1 \alpha$, the expression of SIRT1, involved in inhibiting oxidative stress and the suppression of biogenesis and mitophagy $[38,39]$, was downregulated in sepsisAKI patients. Taken together, sepsis-AKI is associated with upregulation of genes encoding molecules involved in inhibiting inflammation and antioxidant defense in the kidney.

Compared to control subjects, sepsis-AKI patients had upregulated mRNA expression of oxidative damage markers and high levels of mitochondrial DNA damage. Also $48 \mathrm{~h}$ of LPS induction in HUVECs caused an increase in $m n S O D$ expression and mtDNA damage. Although several studies demonstrated increased biomarkers suggestive of mitochondrial dysfunction in sepsis $[10,11,15]$, to our knowledge only one other study so far demonstrated the occurrence of mtDNA damage in patients with sepsis, as illustrated by the depletion of mtDNA defined by RT-qPCR in monocytes and lymphocytes [40]. Extending on the observations of these previous studies, we now directly demonstrate the presence of mtDNA damage in the septic kidney. Whereas mtDNA damage in monocytes and lymphocytes correlated with the APACHE score, we did not find such a correlation between mtDNA damage and APACHE score in sepsisAKI patients, which might be due to the small sample size ( $n=147$ vs $n=12$, respectively). The observed mtDNA damage in the kidney in patients with sepsis-AKI is in line with findings from experimental murine sepsis models, which showed profound damage to mtDNA in skeletal muscle and 50\% mtDNA depletion in the liver [9, 41]. mtDNA damage was associated with increased DNA oxidation (i.e., 8-oxoG) in sepsis-AKI as compared to control subjects, while immunofluorescent staining showed co-localization of DNA oxidation with both nuclei and mitochondria. In line with this observation, sepsis in mice also leads to accumulation of 8-oxoG in mitochondria and mitochondrial dysfunction, as demonstrated in the brain [42]. Hence, mitochondrial dysfunction leading to increased oxidative stress, oxidation of mtDNA and damage that further impairs mitochondrial function might play a key role in the pathophysiology sepsis-AKI.

Mitochondrial quality control mechanisms, consisting of biogenesis (making new mitochondria), fission/ fusion of mitochondria and mitophagy (removal of damaged mitochondria), can counteract mitochondrial damage and subsequent dysfunction [7, 8, 43]. SepsisAKI patients had lower mRNA expression of TFAM (marker for biogenesis) and PINK and PARKIN (markers for mitophagy), but no change in mRNA expression of MFN2 and DRP1 (markers for fusion and fission). HUVECs induced with LPS for 48 h showed a similar pattern, where TFAM was decreased, but no change in 

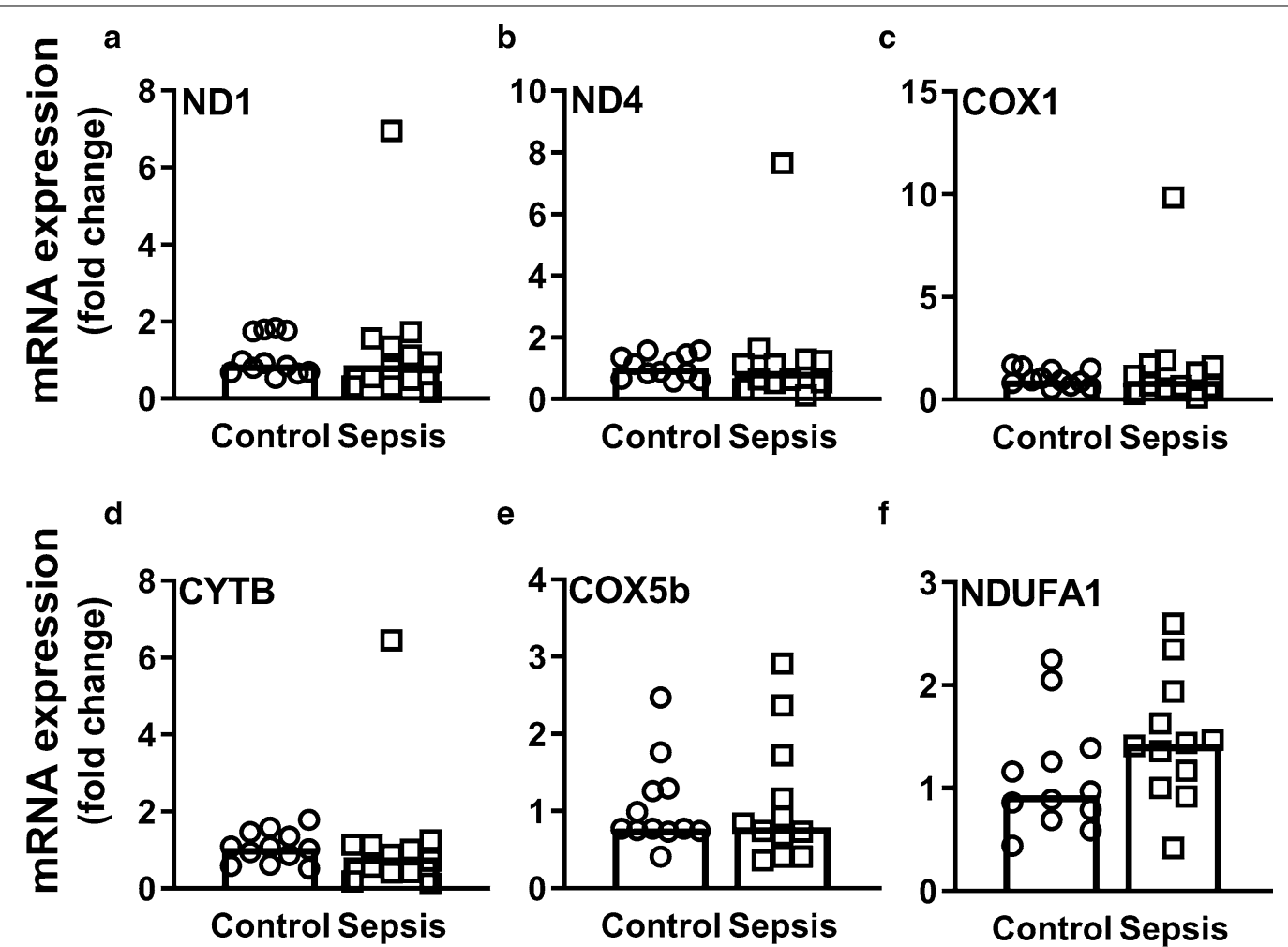

Fig. 8 mRNA expression of mitochondrial electron transport chain complexes. mRNA expression of a ND1, b ND4, c COX1, d CYTB, e COX5b, and $\mathbf{f}$ NDUFA1 as quantified by RT-qPCR. Bars represent median, dots represent individual levels

PINK, MFN2 or DRP1. Similar to our findings, sepsis is associated with increased mRNA expression and protein levels of TFAM in muscle, suggestive of biogenesis and a lowered mitochondrial mass [11]. Adequate compensation of mitochondrial damage seems to play an important role in determining the outcome of sepsis, as mRNA expression of Peroxisome Proliferator-activated Receptor

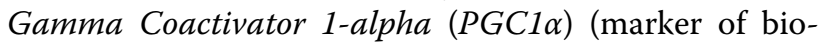
genesis upstream of TFAM) is associated with survival from sepsis [11]. Also, LPS-induced mice with AKI suffer from decreased mRNA expression of PGC1 $\alpha$ in the renal cortex, whereas overexpression of $P G C 1 \alpha$ shows recovery from LPS-induced AKI [15]. The protective role of mitophagy is illustrated by PARK2-deficient mice, which exhibited degradation of mitochondrial functions and impaired recovery of cardiac contractility in sepsis [44]. Additionally, inhibition of mitophagy in mice increases the sensitivity of multiple organ failure and death from sepsis $[44,45]$. Here, we found a decreased expression of PINK1 and PARKIN, the main mitophagy regulators, in the septic kidney, which suggests that removal of damaged mitochondria by mitophagy is impaired. Lastly, we found no changes in mRNA expression DRP1 or MFN2 (markers for fission/fusion) in renal biopsies or LPS treated HUVECs. Accordingly, fission and fusion did not differ between septic patients and controls in human PBMCs [46]. However, since PINK1 and PARKIN mediate degradation of MFN2 and activation of DRP1 to prevent fusion while promoting fission $[47,48]$, we cannot conclude that protein levels or activity of PINK1 and PARKIN and hence fusion/fission are unaltered in sepsis. Together, sepsis is associated with mtDNA damage in sepsis without upregulation of genes encoding for mitochondrial quality control processes to safeguard the mitochondria.

A strength of our study is the use of fresh direct postmortem kidney biopsies from sepsis-AKI patients and control subjects, which allowed us to directly investigate the effect of sepsis on mitochondria in the kidney in association with immunohistochemical analysis, albeit in a small cohort of patients, while other studies estimate kidney and mitochondrial damage indirect using surrogate markers in urine or blood. However, we could only analyze non-survivors, which represent the most severe critically ill patients, as it would be ethically unacceptable to obtain renal biopsies from living patients with sepsis-AKI. Postmortem changes in mRNA expression should be taken into consideration when interpreting our data, but are unlikely to have been of major relevance, as samples were collected as quickly as possible after death 
(24-150-min postmortem), and the kidney is among the less susceptible organs to changes in RNA integrity and gene expression as demonstrated up to 24-h postmortem [49]. Lastly, there is uncertainty as to whether renal cell carcinoma might have affected mitochondrial mass or DNA levels in surrounding healthy tissue. However, mtDNA copy number, DNA content and activities of mitochondrial enzymes are shown to be reduced within RCC tissue [50, 51]. Furthermore, impairment of mitochondrial DNA levels and mass depends on RCC aggressiveness, a trend that is not found in healthy tissue within the same kidney $[52,53]$. Thus, in contrast to effects of cancer on mitochondrial mass and DNA within the tumor, this does not seem to be the case for surrounding tissue. However, even if mitochondrial mass and DNA in surrounding tissue would have been affected by the tumor, this would have led to an underestimation of the effect of sepsis and thus not compromise our findings.

\section{Conclusion}

Our findings shed new light on the contribution of mitochondria in the pathophysiology of sepsis-AKI. We reveal that sepsis induces oxidation of nuclear and mitochondrial DNA and mtDNA damage, without signs of upregulation of mitochondrial quality control mechanisms, resulting in a reduced mitochondrial mass in the septic kidney. These findings are of clinical relevance, as sepsis is the major cause of AKI and death in critically ill patients. Dissecting the molecular mechanisms leading to mitochondrial dysfunction in sepsisAKI is crucial for the development of novel targeted therapies to prevent or treat sepsis-AKI and potentially improve the survival. Since it is not known whether mtDNA damage is repaired after survival from sepsis, our findings might also be of relevance for long-term outcomes of sepsis. Given the role of mitochondria in the pathophysiology of sepsis-AKI, pharmacologic strategies directed at maintaining mitochondrial function, limiting oxidative stress and mtDNA damage, or enhancing mitochondrial quality control to ameliorate mitochondrial damage, might successfully prevent or halt AKI in sepsis.

\footnotetext{
Abbreviations

AKI: Acute kidney injury; APACHE: Acute Physiology and Chronic Health Evaluation; B2M: Beta 2-microglobulin; COX1: Cytochrome C oxidase l; CYTB: Cytochrome B; DRP1: Dynamin-related protein 1; HIF1a: Hypoxia-inducible factor 1-alpha; ICU: Intensive care unit; METC: Medical Ethics Review Committee; MFN2: Mitofusin 2; mnSOD: Manganese superoxide dismutase; mtDNA: Mitochondrial DNA; mRNA: Messenger RNA; ND1: NADH dehydrogenase 1; NGAL: Neutrophil gelatinase-associated lipocalin; OGG1: 8-Oxoguanine DNA glycosylase 1; PCR: Polymerase chain reaction; PGC1 a: Peroxisome proliferatoractivated receptor gamma coactivator 1-alpha; PINK: PTEN-induced putative kinase 1; RIFLE: Risk, Injury, Failure, Loss of kidney function, and End-stage kidney disease; ROS: Reactive oxygen species; RT-qPCR: Reverse transcription
}

quantitative polymerase chain reaction; SAPS II: Simplified Acute Physiology Score II; SIRT1: Sirtuin 1; TFAM: Mitochondrial transcription factor A; TOM20: Translocase of outer mitochondrial membrane 20; UMCG: University Medical Center Groningen.

\section{Acknowledgements}

Not applicable.

\begin{abstract}
Authors' contributions
MVM designed the study and collected the biomaterials. ECVDS and JM performed the experiments. ECVDS, BS, and HRB conceptualized the manuscript. ECVDS analyzed the data and wrote the manuscript. BS, MVM, RHH, $J M$, and HRB edited the manuscript. All authors read and approved the final manuscript.
\end{abstract}

\section{Funding}

Our sepsis research is supported by a grant to HRB from the Dutch Kidney Foundation (16OKG06) and by a MD/PhD grant from the Junior Scientific Masterclass (JSM, UMCG) to ECVDS.

\section{Availability of data and materials}

The datasets used and/or analyzed during the current study are available from the corresponding author on reasonable request.

\section{Ethics approval and consent to participate}

The Medical Ethics Review Committee (METC) of the UMCG reviewed and approved this study (METC 2011/372).

\section{Consent for publication}

Not applicable.

\section{Competing interests}

The authors declare that they have no competing interests.

\section{Author details}

${ }^{1}$ Department of Clinical Pharmacy and Pharmacology, University of Groningen, University Medical Center Groningen, P.O. Box 30.001, EB70, 9700 RB Groningen, The Netherlands. ${ }^{2}$ Department of Critical Care, University of Groningen, University Medical Center Groningen, Groningen, The Netherlands. ${ }^{3}$ Department of Pathology and Medical Biology, Medical Biology Section, University of Groningen, University Medical Center Groningen, Groningen, The Netherlands. ${ }^{4}$ Department of Internal Medicine, University of Groningen, University Medical Center Groningen, Groningen, The Netherlands.

Received: 25 September 2020 Accepted: 2 December 2020

Published online: 25 January 2021

\section{References}

1. Angus DC, van der Poll T. Severe sepsis and septic shock. N Engl J Med. 2013;369(9):840-51.

2. Cecconi M, Evans L, Levy M, Rhodes A. Sepsis and septic shock. Lancet. 2018;392(10141):75-87.

3. Reinhart K, Daniels R, Kissoon N, Machado FR, Schachter RD, Finfer S. Recognizing sepsis as a global health priority - $\mathrm{a}$ WHO resolution. N Engl J Med. 2017:377(5):414-7.

4. Gotts JE, Matthay MA. Sepsis: pathophysiology and clinical management. BMJ. 2016;353:11585.

5. Schrier RW, Wang W. Acute renal failure and sepsis. N Engl J Med. 2004;351 (2):159-69.

6. Bellomo R, Kellum JA, Ronco C, Wald R, Martensson J, Maiden M, et al. Acute kidney injury in sepsis. Intensive Care Med. 2017;43(6):816-28.

7. Emma F, Montini G, Parikh SM, Salviati L. Mitochondrial dysfunction in inherited renal disease and acute kidney injury. Nat Rev Nephrol. 2016;12(5):267-80.

8. Parikh SM, Yang Y, He L, Tang C, Zhan M, Dong Z. Mitochondrial function and disturbances in the septic kidney. Semin Nephrol. 2015;35(1):108-19.

9. Rocheteau P, Chatre L, Briand D, Mebarki M, Jouvion G, Bardon J, et al. Sepsis induces long-term metabolic and mitochondrial muscle stem cell 
dysfunction amenable by mesenchymal stem cell therapy. Nat Commun. 2015;6:10145.

10. Brealey D, Brand M, Hargreaves I, Heales S, Land J, Smolenski R, et al. Association between mitochondrial dysfunction and severity and outcome of septic shock. Lancet. 2002;360(9328):219-23.

11. Carre JE, Orban JC, Re L, Felsmann K, Iffert W, Bauer M, et al. Survival in critical illness is associated with early activation of mitochondrial biogenesis. Am J Respir Crit Care Med. 2010;182(6):745-51.

12. Supinski GS, Callahan LA. Polyethylene glycol-superoxide dismutase prevents endotoxin-induced cardiac dysfunction. Am J Respir Crit Care Med. 2006;173(11):1240-7.

13. Suliman HB, Carraway MS, Piantadosi CA. Postlipopolysaccharide oxidative damage of mitochondrial DNA. Am J Respir Crit Care Med. 2003;167(4):570-9.

14. Hahn A, Zuryn S. Mitochondrial genome (mtDNA) mutations that generate reactive oxygen species. Antioxidants (Basel). 2019;8(9):392.

15. Tran M, Tam D, Bardia A, Bhasin M, Rowe GC, Kher A, et al. PGC-1 alpha promotes recovery after acute kidney injury during systemic inflammation in mice. J Clin Invest. 2011;121(10):4003-14.

16. Gunst J, Derese I, Aertgeerts A, Ververs EJ, Wauters A, Van den Berghe G, et al. Insufficient autophagy contributes to mitochondrial dysfunction, organ failure, and adverse outcome in an animal model of critical illness. Crit Care Med. 2013;41(1):182-94.

17. Funk JA, Schnellmann RG. Persistent disruption of mitochondrial homeostasis after acute kidney injury. Am J Physiol Renal Physiol. 2012;302(7):F853-64.

18. Tran MT, Zsengeller ZK, Berg AH, Khankin EV, Bhasin MK, Kim W, et al. PGC1alpha drives NAD biosynthesis linking oxidative metabolism to renal protection. Nature. 2016;531(7595):528-32.

19. Stallons LJ, Funk JA, Schnellmann RG. Mitochondrial homeostasis in acute organ failure. Curr Pathobiol Rep. 2013;1 (3):169-77.

20. Levy MM, Fink MP, Marshall JC, Abraham E, Angus D, Cook D, et al. 2001 SCCM/ESICM/ACCP/ATS/SIS international sepsis definitions conference. Crit Care Med. 2003;31(4):1250-6.

21. Bellomo R, Ronco C, Kellum JA, Mehta RL, Palevsky P. Acute Dialysis Quality Initiative w. Acute renal failure - definition, outcome measures, animal models, fluid therapy and information technology needs: the Second International Consensus Conference of the Acute Dialysis Quality Initiative (ADQI) Group. Crit Care. 2004;8(4):R204-12.

22. Knaus WA, Zimmerman JE, Wagner DP, Draper EA, Lawrence DE. APACHEacute physiology and chronic health evaluation: a physiologically based classification system. Crit Care Med. 1981;9(8):591-7.

23. Le Gall JR, Lemeshow S, Saulnier F. A new Simplified Acute Physiology Score (SAPS II) based on a European/North American multicenter study. JAMA. 1993;270(24):2957-63.

24. Aslan A, van den Heuvel MC, Stegeman CA, Popa ER, Leliveld AM, Molema G, et al. Kidney histopathology in lethal human sepsis. Crit Care. 2018;22(1):359.

25. Schneider CA, Rasband WS, Eliceiri KW. NIH Image to ImageJ: 25 years of image analysis. Nat Methods. 2012;9(7):671-5.

26. Jou-Valencia D, Molema G, Popa E, Aslan A, van Dijk F, Mencke R, et al. Renal Klotho is reduced in septic patients and pretreatment with recombinant Klotho attenuates organ injury in lipopolysaccharide-challenged mice. Crit Care Med. 2018;46(12):e1 196-203.

27. Exline MC, Crouser ED. Mitochondrial mechanisms of sepsis-induced organ failure. Front Biosci. 2008;13:5030-41.

28. Wu Y, Yao YM, Lu ZQ. Mitochondrial quality control mechanisms as potential therapeutic targets in sepsis-induced multiple organ failure. J Mol Med (Berl). 2019;97(4):451-62.

29. Martins PS, Kallas EG, Neto MC, Dalboni MA, Blecher S, Salomao R. Upregulation of reactive oxygen species generation and phagocytosis, and increased apoptosis in human neutrophils during severe sepsis and septic shock. Shock. 2003;20(3):208-12.

30. Reitsema VA, Star BS, de Jager VD, van Meurs M, Henning RH, Bouma HR. Metabolic resuscitation strategies to prevent organ dysfunction in sepsis. Antioxid Redox Signal. 2019;31(2):134-52.

31. Bahmani P, Halabian R, Rouhbakhsh M, Roushandeh AM, Masroori N, Ebrahimi M, et al. Neutrophil gelatinase-associated lipocalin induces the expression of heme oxygenase-1 and superoxide dismutase 1, 2. Cell Stress Chaperones. 2010;15(4):395-403.
32. Fitzpatrick SF. Immunometabolism and sepsis: a role for HIF? Front Mol Biosci. 2019;6:85.

33. Patil NK, Parajuli N, MacMillan-Crow LA, Mayeux PR. Inactivation of renal mitochondrial respiratory complexes and manganese superoxide dismutase during sepsis: mitochondria-targeted antioxidant mitigates injury. Am J Physiol Renal Physiol. 2014;306(7):F734-43.

34. Bagshaw SM, Bennett M, Haase M, Haase-Fielitz A, Egi M, Morimatsu $H$, et al. Plasma and urine neutrophil gelatinase-associated lipocalin in septic versus non-septic acute kidney injury in critical illness. Intensive Care Med. 2010;36(3):452-61.

35. Choumar A, Tarhuni A, Letteron P, Reyl-Desmars F, Dauhoo N, Damasse J, et al. Lipopolysaccharide-induced mitochondrial DNA depletion. Antioxid Redox Signal. 2011;15(11):2837-54.

36. Wang $Y$, Wang $X$, Zhang $L$, Zhang R. Alleviation of acute lung injury in rats with sepsis by resveratrol via the phosphatidylinositol 3-kinase/nuclear factor-erythroid 2 related factor 2/heme oxygenase-1 (PI3K/Nrf2/HO-1) pathway. Med Sci Monit. 2018;24:3604-11.

37. Textoris J, Beaufils N, Quintana G, Ben Lassoued A, Zieleskiewicz L, Wiramus $\mathrm{S}$, et al. Hypoxia-inducible factor (HIF1alpha) gene expression in human shock states. Crit Care. 2012;16(4):R120.

38. Tang BL. Sirt1 and the mitochondria. Mol Cells. 2016;39(2):87-95.

39. Salminen A, Kaarniranta K, Kauppinen A. Crosstalk between oxidative stress and SIRT1: impact on the aging process. Int J Mol Sci. 2013;14(2):3834-59.

40. Pyle A, Burn DJ, Gordon C, Swan C, Chinnery PF, Baudouin SV. Fall in circulating mononuclear cell mitochondrial DNA content in human sepsis. Intensive Care Med. 2010;36(6):956-62.

41. Gonzalez AS, Elguero ME, Finocchietto P, Holod S, Romorini L, Miriuka SG, et al. Abnormal mitochondrial fusion-fission balance contributes to the progression of experimental sepsis. Free Radic Res. 2014;48(7):769-83.

42. Leon J, Sakumi K, Castillo E, Sheng Z, Oka S, Nakabeppu Y. 8-Oxoguanine accumulation in mitochondrial DNA causes mitochondrial dysfunction and impairs neuritogenesis in cultured adult mouse cortical neurons under oxidative conditions. Sci Rep. 2016;6:22086.

43. Friedman JR, Nunnari J. Mitochondrial form and function. Nature. 2014;505(7483):335-43.

44. Piquereau J, Godin R, Deschenes S, Bessi VL, Mofarrahi M, Hussain SN, et al. Protective role of PARK2/Parkin in sepsis-induced cardiac contractile and mitochondrial dysfunction. Autophagy. 2013;9(11):1837-51.

45. Kang R, Zeng L, Xie Y, Yan Z, Zhou B, Cao L, et al. A novel PINK1- and PARK2-dependent protective neuroimmune pathway in lethal sepsis. Autophagy. 2016;12(12):2374-85.

46. Jang DH, Greenwood JC, Owiredu S, Ranganathan A, Eckmann DM. Mitochondrial networking in human blood cells with application in acute care illnesses. Mitochondrion. 2019;44:27-34.

47. Jin SM, Youle RJ. PINK1 - and Parkin-mediated mitophagy at a glance. J Cell Sci. 2012;125(Pt 4):795-9.

48. Buhlman L, Damiano M, Bertolin G, Ferrando-Miguel R, Lombes A, Brice $A$, et al. Functional interplay between Parkin and Drp1 in mitochondrial fission and clearance. Biochim Biophys Acta. 2014;1843(9):2012-26.

49. Ferreira PG, Munoz-Aguirre M, Reverter F, Sa Godinho CP, Sousa A, Amadoz A, et al. The effects of death and post-mortem cold ischemia on human tissue transcriptomes. Nat Commun. 2018:9(1):490.

50. Lin CS, Lee HT, Lee MH, Pan SC, Ke CY, Chiu AW, et al. Role of mitochondrial DNA copy number alteration in human renal cell carcinoma. Int J Mol Sci. 2016;17(6):814.

51. Meierhofer D, Mayr JA, Foetschl U, Berger A, Fink K, Schmeller N, et al. Decrease of mitochondrial DNA content and energy metabolism in renal cell carcinoma. Carcinogenesis. 2004;25(6):1005-10.

52. Simonnet H, Alazard N, Pfeiffer K, Gallou C, Beroud C, Demont J, et al. Low mitochondrial respiratory chain content correlates with tumor aggressiveness in renal cell carcinoma. Carcinogenesis. 2002;23(5):759-68.

53. Yusenko MV, Ruppert T, Kovacs G. Analysis of differentially expressed mitochondrial proteins in chromophobe renal cell carcinomas and renal oncocytomas by 2-D gel electrophoresis. Int J Biol Sci. 2010;6(3):213-24.

\section{Publisher's Note}

Springer Nature remains neutral with regard to jurisdictional claims in published maps and institutional affiliations. 